\title{
Journal of Failure Analysis and Prevention Volume 18 Best Paper Award
}

Dr. Michael E. Stevenson, editor of the Journal of Failure Analysis and Prevention (JFAP), announced that the JFAP Volume 18 Best Paper is "Investigation and Recommendations on Bottom-Dented Petroleum Pipelines" by Erik Mueller, Xiaohu Liu, Ravindra Chhatre, and Adrienne Lamm. The winning article was published in the February 2018 issue of JFAP.

The award, in addition to the recognition, includes a plaque and $\$ 1000$ worth of ASM International products and services. The Best Paper was selected by the Editorial Board of the journal from all papers published in Volume 18.

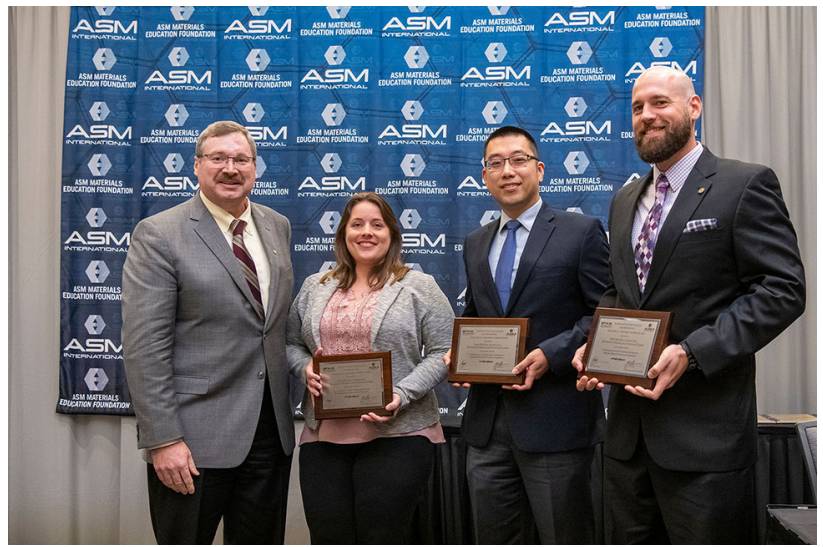

David Furrer, President, ASM International (left), presents the Volume 18 JFAP Best Paper Award plaques to Adrienne Lamm, Xiaohu Liu, and Erik Mueller during MS\&T '19. 